\title{
Person-first Language Aspects of Communication in Health and Mental Health Settings
}

Sabine Bährer-Kohler

Dr. Bährer-Kohler \& Partners, Peter-Merian-Str. 58, PO BOX 3244, 4002 Basel, Switzerland

\section{Introduction}

To reach good health, and to promote prevention of disease in the family \& community, to be engaged in an ongoing dialogue with clients and their family members that brings about understanding, acceptance, cooperation, and an identification of common goals and e.g. related care plans, language competences are important factors for all participants in the field of health care. Communication has to be, whenever possible, accurately in a language that clients are able to understand [1].

\section{Reflection}

Language is not only at the heart of psychiatric practice [2]. It is at the heart of health promotion in general. That people with the same language have difficulties to understand each other in the health context can have reasons, that people with different languages are unable or have difficulties to understand each other is evident $[2,3]$ Patient-provider language concordance has an important role in communication barriers and health care [4]. Language discrepancies may result in general in an increased stress, for the individual, their families, and professionals [5]. Misunderstandings can have huge impacts, e.g. for lifethreatening [5]. Language barriers are associated with an increased risk of hospital admission, increased risk of intubation for asthmatics, greater number of reported adverse drug reactions, and lower rates of best or optimal pain medication or treatment [6].

Professionals should be aware that e.g. dual language children of immigrants, adequately functioning in two languages and more at home and e.g. at school may be associated with their health and wellbeing [7]. In several sectors e.g. related to the communication with the rising number of migrant patients [5], or general with migrants as the proportion of people living outside their country of birth [8], misunderstandings and errors in the communication are increasingly likely.

The service use of migrants can often be contradictory [9]. Current scientific analyses document the need for more epidemiological data about it [10].

Compelling evidence exist that language barriers have an adverse effect especially on initial access to health services [6] and there is evidence that clients face significant barriers to first contact with a variety of service providers [6].

In addition, the access to mental health services and the use of, and with optimal treatment may be a serious problem for linguistic and cultural minorities in many countries [11]. It is documented that poor language ability and a lack of understanding of the mainstream culture can be barriers especially to access mental health services [12]

Professionals have to be aware that different languages in the health and mental health context can influence an effective communication and can avoid necessary health care and basic needs.

\section{Publication History:}

Received: September 15, 2016

Accepted: September 26, 2016

Published: September 28, 2016

\section{Keywords:}

Communication, Language, Global Health, Global Mental Health, Access Healthcare, Global Engagement, Standards, Legislations

\section{Possible ways to step forward}

To reach a better communication in healthcare settings, the following aspects should be integrated.

Awareness and activity: Awareness about e.g. later-life immigration and a lack of dominant language competency. They may present many challenges to health and mental health for older adults [13]. Awareness of the importance of provider-client communication and the interpretation within the health care professions are requested [6]. Unprofessional ad-hoc solutions have to be avoided [14].

Individual solutions have to be pointed out, also under difficult circumstances for everybody and for every client with the inclusion of the family support system, to increase adherence to treatment\& counselling and to reduce barriers [15].

Exploration: It is more than effective that professionals explore the nature of difficulties [5], and implement when necessary other professionals, like interpreters or bilingual providers [6], social networks and capacities.

Trainings: Language training programs or formal trainings for professionals can be supportive $[5,16]$. Never less counseling in a second language can mean that professionals face experiences like of somewhat of an accident or coincidence [17].

More implementations of guidelines and training initiatives in primary care: (G/TIs) are often available to support communication in cross-cultural consultations and treatments but are rarely implemented in routine practice in primary care [18].

Certification: certifications of healthcare interpreters should be addressed or should be developed [19]. In the US the state Washington

*Corresponding Author: Prof. Sabine Bährer-Kohler, Dr. Bährer-Kohler \& Partners, Peter-Merian-Str. 58, PO BOX 3244, 4002 Basel, Switzerland; E-mail: sabine.baehrer@datacomm.ch

Citation: Bährer-Kohler S (2016) Person-first Language Aspects of Communication in Health and Mental Health Settings. Int J Community Fam Med 1: 116. doi: https://doi.org/10.15344/2456-3498/2016/116

Copyright: () 2016 Bertram. This is an open-access article distributed under the terms of the Creative Commons Attribution License, which permits unrestricted use, distribution, and reproduction in any medium, provided the original author and source are credited. 
Citation: Bährer-Kohler S (2016) Person-first Language Aspects of Communication in Health and Mental Health Settings. Int J Community Fam Med 1: 116. doi: https://doi.org/10.15344/2456-3498/2016/116

Page 2 of 2

was the first state to establish a healthcare interpreter certification program [19], the Language Interpreter Services and Translations (LIST) was formed in 1991.

Dissemination of information: the dissemination of informational brochures and letters on healthcare possibilities produced in several languages can be useful and supportive [19]

Standards \& laws: Detailed national standards related to language access to health and mental health care should be developed in every country around the globe. As example in the United States in January 2006, at least 43 states as demographically and geographically diverse as California had enacted laws addressing language access in healthcare settings [19].

Strategies \& legislations: More national strategies like the CMS Strategic Language Access Plan (LAP) 2014 [20] and international strategies are requested to promote the topic and to involve policymakers, stakeholders, health service planners, responsible governments, and health organizations. Like the Study of the European Commission on Public Service Translation in Cross-border Healthcare in 2015 concluded, there is an absence of formal language guidance e.g. in EU legislation in this field. This capture and request for implications of and for policy makers, healthcare providers, educators, translators and interpreters and others serving the needs of linguistically and culturally diverse clients and minorities.

\section{Competing Interests}

The author(s) declare that they have no competing interests.

\section{References}

1. Institute of Medicine (US) Committee on the Health Professions Education Summit; Editors: Ann C.Greiner and Elisa Knebel (2003) Health Professions Education: A Bridge to Quality. National Academies Press (US).

2. Kilian S, Swartz L, Chiliza B (2015) Doing their best: strategies used by South African clinicians in working with psychiatric inpatients across a language barrier. Glob Health Action 8: 10 .

3. Swartz L, Kilian S, Twesigye J, Attah D, Chiliza B (2014) Language, culture and task shifting-an emerging challenge for global mental health. Glob Health Action 7: 23433

4. Gonzalez HM, Vega WA, Tarraf W (2010) Health Care Quality Perceptions among Foreign-Born Latinos and the Importance of Speaking the Same Language. J Am Board Fam Med 23: 745.

5. Meuter RFI, Gallois C, Segalowitz NS, Ryder AG, Hocking J (2015) Overcoming language barriers in healthcare: A protocol for investigating safe and effective communication when patients or clinicians use a second language. BMC Health Serv Res 15: 371.

6. Bowen S (2001) Language Barriers in Access to Health Care. Health Canada.

7. Collins BA (2010) Multilingual/Multicultural Studies, Steinhardt School of Culture, Education, and Human Development. New York: New York University; Dual Language Competences and Psychosocial Wellbeing of Children of Immigrants.

8. United Nations (2013) Trends in International Migration Stock. New York: United Nations.

9. Rechel B, Mladovsky P, Ingleby D, Mackenbach JP, McKee M (2013) Migration and Health in an Increasingly Diverse Europe. The Lancet 381 1235-1245.

10. Norredam M, Nielsen SS, Krasnik A (2010) Migrants' Utilization of Somatic Healthcare Services in Europe-A Systematic Review. Eur J Public Health 20: $555-563$
11. Tempier R, Bouattane EM, Hirdes JP (2015) Access to psychiatrists by French-speaking patients in Ontario hospitals 2005 to 2013. Health Manage Forum 28: 167-171.

12. Li HZ, Browne AJ (2000) Defining mental illness and accessing mental health services: perspectives of Asian Canadians. Can J Commun Ment Health 19: 143-159.

13. Taylor LE, Taylor-Henley S, Doan L (2005) Older immigrants: language competencies and mental health. Can J Commun Ment Health. Autumn 24: 23-34.

14. European Commission/ Angelelli, CV (2015) Study on Public Service Translation in Cross-border Healthcare.

15. Kramer EJ, Kwong K, Lee E, Chung $\mathrm{H}$ (2002) Cultural factors influencing the mental health of Asian Americans. West J Med 176: 227-231.

16. Castaño MT, Biever JL, Gonzalez CG, Anderson KB (2007) Challenges of providing mental health services in Spanish. Professional Psychology: Research \& Practice 38: 667-673.

17. Trepal H, Ivers N, Lopez A (2014) Students' Experiences with Bilingual Counseling. The Journal of Counselor Preparation and Supervision 6: 2.

18. Lionis C, Papadakaki M, Saridaki A, Dowrick C, O'Donnell CA, et al. (2016) Engaging migrants and other stakeholders to improve communication in cross-cultural consultation in primary care: a theoretically informed participatory study. BMJ Open 6: e010822.

19. Chen AH, Youdelman MK, Brooks J (2007) The Legal Framework for Language Access in Healthcare Settings: Title VI and Beyond. J Gen Intern Med 22: 362-367.

20. CMS- Centers for Medicare \& Medicaid Services (2014) Strategic Language Access Plan (LAP). To improve access to CMS federally. Conducted activities by persons with limited English proficiency (LEP). 